\title{
Bioremediation of Atrazine Herbicide Contaminated Soil Using Different Bioremediation Strategies
}

\section{OLU-AROTIOWA, OA; AJANI, AO; AREMU, MO; *AGARRY, SE}

\author{
Biochemical and Bioenvironmental Engineering Laboratory, Department of Chemical Engineering, Ladoke Akintola University of \\ Technology, Ogbomoso, Nigeria \\ *Corresponding author Email: sam_agarry@yahoo.com
}

\begin{abstract}
This study evaluated the bioremediation of atrazine herbicide contaminated agricultural soil under different bioremediation strategies using indigenous Pseudomonas aeruginosa, Bacillus subtilis and Aspergillus niger as bioaugmentation agents and poultry droppings as biostimulation agent. The results showed that bioaugmentation with Pseudomonas aeruginosa, bioaugmentation with Bacillus subtilis, bioaugmentation with Aspergillus niger, bioaugmentation with bacterial-fungal consortium (Pseudomonas aeruginosa, Bacillus subtilis and Aspergillus niger), biostimulation with poultry droppings, and combined biougmentation and biostimulation (Pseudomonas aeruginosa, Bacillus subtilis, Aspergillus niger and poultry droppings) resulted in maximum atrazine biodegradation of about $97 \%$, $95 \%, 84 \%, 99 \%, 100 \%$ and $100 \%$, respectively. The kinetics of atrazine biodegradation in the soil were modelled using first-order kinetic model and the biodegradation half-life estimated. The first order kinetic model adequately described the kinetics of atrazine biodegradation in soil under the different bioremediation strategies. The rate constants $\left(k_{1}\right)$ of atrazine biodegradation in soil subjected to bioaugmentations with Pseudomonas aeruginosa, Bacillus subtilis, Aspergillus niger, and bacterial-fungal consortium ranges between 0.059 day $^{-1}$ and 0.191 day $^{-1}$ while for that subjected to natural bioattenuation, biostimulation and combined bioaugmentation and biostimulation are 0.026 day $^{-1}, 0.164$ day $^{-}$

${ }^{1}$ and 0.279 day $^{-1}$, respectively. The half-life $\left(t_{1 / 2}\right)$ of atrazine biodegradation in soil under natural bioattenuation was obtained to be 26.7 days. This was reduced to between 2.5 and 11.7 days under the application of bioaugmentation, biostimulation and combined bioaugmentation and biostimulation strategies. The bioremediation efficiencies of the different bioremediation strategies in influencing atrazine biodegradation or removal is of the following order: Combined bioaugmentation and biostimulation $>$ Bioaugmentation with bacterial-fungal consortium $>$ Biostimulation with poultry droppings $>$ Bioaugmentation with Pseudomonas aeruginosa $>$ Bioaugmentation with Bacillus subtilis $>$ Bioaugmentation with Aspergillus niger $>$ Natural bioattenuation.
\end{abstract}

\section{DOI: https://dx.doi.org/10.4314/jasem.v23i1.16}

Copyright: Copyright $(\odot 2019$ Olu-Arotiowa et al. This is an open access article distributed under the Creative Commons Attribution License (CCL), which permits unrestricted use, distribution, and reproduction in any medium, provided the original work is properly cited.

Dates: Received: 02 December 2018; Revised: 14 January 2019; Accepted 20 January 2019

Keywords: Atrazine; Bioaugmentation; Bioremediation; Biostimulation

World-wide, herbicides have been widely utilized for controlling noxious or undesirable plant growth generally referred to as weeds in crop and non-crop areas and this has contributed greatly to modern agriculture (Wang et al., 2018). One of the most widely used herbicides in agriculture is atrazine (2chloro-4-ethylamino-6-isopropylamino-1,3,5-

triazine) (Ackerman, 2007; El-Bestawy et al., 2014; Cao et al., 2018). It is a non-polar, non-volatile and low soluble compound (El-Bestawy et al., 2014). It is primarily applied as a selective herbicide for controlling broad-leaf and some grassy weeds in crop production such as corn, maize, pineapple, sorghum and sugar cane. (El-Bestawy et al., 2014; Sopid, 2016; Zhao et al., 2018; Cao et al., 2018) and as a nonselective herbicide for non-cropped fallow lands and industrial lands (Ghosh and Phillip, 2006; Solomon et al., 2013). Nevertheless, the long-term and excessive application of atrazine could lead to its high concentrations presence and persistence in the soil which could be dissipated through leaching into ground water and drinking water as well as washed (as run-off) into surface water, if applied prior to irrigation or heavy rainfall (Nasseri et al., 2009; Dehghani et al., 2010). The maximum atrazine contaminant level in drinking water is $3.0 \mu \mathrm{gL}^{-1}$ (USEPA, 1990). However, the type of soil determines the mobility and environmental fate of Atrazine through sorption to soil particles. Atrazine is more readily adsorbed on muck or clay soils than on soils of low clay and organic matter content; therefore, adsorption to certain soil constituents significantly limits the downward movement or leaching (Dehghani et al., 2005; Correia et al., 2007; Danrong et al., 2009).

Atrazine has been classified as a priority pollutant 
(Cao et al., 2018) that is toxic (Muñoz-Leoz et al., 2011; Imfeld and Vuilleumier, 2012; Zhao et al., 2018) and carcinogenic (VanLeeuwen et al., 1999; Zhao et al., 2017). It is harmful by inhalation and swallowing as well as by contact with the skin (Extension Toxicology Network, 1996; El-Bestawy et al., 2014). Additionally, atrazine has been reported to possess long-term reproductive and endocrinedisrupting effects, epidemiological link to low sperm counts in men and a probable human carcinogen (VanLeeuwen et al., 1999; Lasserre et al., 2009; Zhao et al., 2017) that causes breast and ovarian cancer (Wang et al., 2018). Therefore, the toxicity of atrazine has raised serious concerns and the need to remediate the soil contaminated with it. There are conventional physical and chemical technologies for soil remediation, however, they have the disadvantages of high economic costs, formation of secondary contaminants and damage to soil organisms (Cao et al., 2018). Innovative strategies for remediating atrazine-contaminated soils are critically needed (Lima et al., 2009; Pandey et al., 2009; Cao et al., 2018).

Bioremediation which is the use of microorganisms or plants has been considered a cost-effective, environmentally friendly strategy to solve soil contamination (Gregoire et al., 2008; Agnello et al., 2016). Thus in recent years, bioremediation has aroused increasing concern in the field of contaminated soil remediation (Agarry et al., 2013; Agnello et al., 2016; Agarry, 2018). It is currently being used to clean a wide variety of chemicals. In soil, many microorganisms and plants play the major role in the biodegradation and elimination of chemicals converting them into simpler non-toxic compounds (Marecik et al., 2008). Some reports have demonstrated the ability of some soil microorganisms to degrade atrazine partially or totally directing it to carbon dioxide and ammonia formation (Rosseaux et al., 2001).

Therefore, this study aimed to experimentally investigate and evaluate the bioremediation of atrazine contaminated agricultural soil under different bioremediation strategies of bioaugmentation, biostimulation, bioaugmentation coupled with biostimulation (i.e. combined bioaugmentation and biostimulation), and natural bioattenuation.

\section{MATERIALS AND METHODS}

Material: The apparatus and equipment used includes the following: $500 \mathrm{ml}$ measuring cylinder, $500 \mathrm{ml}$ conical flasks, test tubes, glass slides, staining rack, filter paper, sterile earthen pots, needles and syringes, pipette, cotton wool, inoculating loop, aluminum foil, spatula, vortex mixer, laboratory incubator $37{ }^{\circ} \mathrm{C}$ (DNP-9052), compound microscope, autoclave (Yx280A), and electrical weighing balance (Ohaus PA512), measuring tape. The reagents and chemicals used are:atrazine, ethanol, distilled water, safranin, nhexane, acetone, crystal violet, Grams iodine, nutrient agar (NA), nutrient broth (NB), Eosin methylene blue (EMB), potato dextrose agar (PDA), potato dextrose broth (PDB) and Mac Conkey.

Collection and Preparation of Sample: Agricultural soil was collected from Landmark University Teaching and Research Farm, Omu-Aran, Kwara state, Nigeria. The farm had been planted with maize crop and leguminous crop on an annual rotation since 2014. The soil samples were obtained from the top 0 $30 \mathrm{~cm}$ using a shovel. The soil samples were dried, homogenized, passed through a $2 \mathrm{~mm}$ sieve and then stored in a polyethylene bag. The poultry droppings used as nutrients for biostimulation were collected from Landmark University Commercial Farm. The poultry droppings were sun dried, grinded and sieved to obtain uniform size particles. The particles were mixed with water and the mixture was allowed to compost for two weeks with regular mixing. The atrazine [6-chloro-N2-ethyl-N4-isopropyl-1, 3, 5triazine-2, 4-diamine] (Figure 1) used as the model herbicide was purchased from an Agro- chemicals store in Omu-Aran, Kwara State, Nigeria.

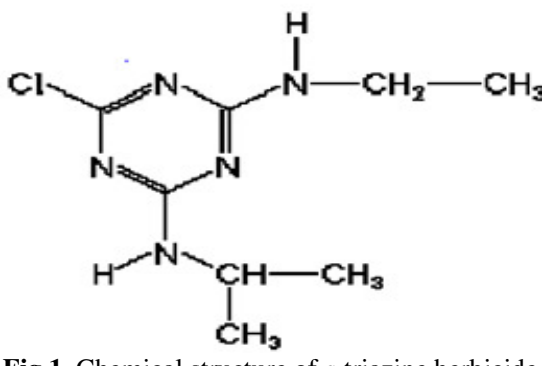

Fig 1. Chemical structure of $s$-triazine herbicide

Characterization and Artificial Contamination of Soil Sample: The collected soil and poultry dropping samples were characterized for physical and chemical properties using standard methods (APHA, 2005). The characterized soil $(1 \mathrm{~kg})$ was distributed into two different aluminum cores. Different volumes of the atrazine herbicide (10 and $20 \mathrm{ml}$ ) was added to the soil in each of the two aluminum cores, respectively. The cores and its contents were placed under a green vegetation area within the university environment and left for 30 days to allow for aging and development of microorganisms that are capable of utilizing atrazine as source of carbon and energy. Within this period, small volume of water was added to the contents in the 
aluminum cores and stirred at regular intervals to ensure proper aeration and even distribution of temperature needed for microbial species development.

Table 1: Physicochemical Characteristics of Uncontaminated Soil

\begin{tabular}{lll}
\hline Parameters & $\begin{array}{l}\text { Un-impacted } \\
\text { Soil }\end{array}$ & $\begin{array}{l}\text { Poultry } \\
\text { Droppings }\end{array}$ \\
\hline Total nitrogen $(\%)$ & $1.32 \pm 0.01$ & $1.62 \pm 0.02$ \\
Total organic carbon $(\%)$ & $0.66 \pm 0.03$ & $35.6 \pm 1.12$ \\
Available phosphorus $(\%)$ & $0.28 \pm 0.02$ & $1.56 \pm 0.01$ \\
Potassium $(\%)$ & $0.16 \pm 0.03$ & $0.34 \pm 0.02$ \\
pH & $6.8 \pm 0.02$ & $6.5 \pm 0.1$ \\
Moisture content $(\%)$ & $7.3 \pm 0.3$ & $11.8 \pm 0.2$ \\
\hline
\end{tabular}

Isolation, Characterization and Identification of Microbial Species: The serial dilution and spread plate techniques (APHA, 2005) using NA, EMB and PDA were employed for the isolation of microorganisms in soil and poultry droppings. One gram each of the soil contaminated with $20 \mathrm{ml}$ and $30 \mathrm{ml}$ of atrazine herbicide was introduced into two (2) sterilized conical flask containing $50 \mathrm{ml}$ of de-ionized water. Vortex mixer was used to mix it and then labelled as stock solutions. $1 \mathrm{ml}$ was taken from each of the stock solutions and dispensed into two different sterilized test tubes containing $9 \mathrm{ml}$ each of de-ionized water and mixed using a vortex mixer and labelled as $10^{-1} .1 \mathrm{ml}$ was then drawn from each of the test tubes labelled 10 ${ }^{1}$ and dispensed into another two separate sterilized test tubes and mixed with vortex mixer and labelled $10^{-2}$. This same procedure was repeated for the rest of the test tubes and labelled $10^{-3}$ to $10^{-10}$, respectively. This process is called serial dilution. After the serial dilution, $1 \mathrm{ml}$ was taken from each of the test tubes labelled $10^{-2}, 10^{-4}, 10^{-6}, 10^{-8}$, and $10^{-10}$ and introduced into 10 different sterilized Petri dishes containing EMB agar and then allowed to solidify. The same procedure was done for PDA and NA. The Petri dishes with EMB and NA were inverted and kept in an incubator at $37{ }^{\circ} \mathrm{C}$ for $18-24 \mathrm{~h}$, while the Petri dishes with PDA were inverted and kept at ambient temperature $\left(27^{\circ} \mathrm{C}\right)$ for $72 \mathrm{~h}$ to allow for microbial growth. The bacterial and fungal colonies isolated from soil contaminated with $20 \mathrm{ml}$ and $30 \mathrm{ml}$ of atrazine herbicide were further selected for colony purification by sub-culturing and for further evaluation of their capacity to utilize atrazine herbicide. The colonies considered to be visually different were streaked separately on NA, EMB, MacConkey and PDA agar plates containing $30 \mathrm{ml}$ of atrazine herbicide and incubated at $37{ }^{\circ} \mathrm{C}$. This procedure was repeated severally to ascertain the purity of the isolated colonies. To be able to characterize the isolated bacterial and fungal isolates, several biochemical tests (citrate test, indole test, catalase test, oxidase test, urease test, mannitol test, methyl red/Voges-Proskauer (MR/VP) test) were carried out on the samples. The shape and morphology of the bacterial and fungal cells were determined using light microscopy (Granados and Villaverde, 1996), while identification of the isolates was made using Bergey's Manual of Determinative Bacteriology (Krieg et al., 1994). Bacteria and fungi isolated from the atrazine contaminated soil include Pseudomonas aeruginosa, Acetobacter sp, Bacillus subtilis, Flavobacterium sp., and Aspergillus niger. The indigenous microorganisms present in the unimpacted soil were identified to be made up of Pseudomonas aureofaciens, Curvularia sp, Alternaria sp, Candida famata, Phialoplora sp., and Penicillum sp., respectively. Meanwhile, the microorganisms present in the poultry droppings were identified to be made up of mainly Escherichia coli, Flavobacterium, Pseudomonas sp., Staphylococcus sp., and Mucor. The isolated pure colonies of Pseudomonas aeruginosa, Bacillus subtilis, Aspergillus niger and their consortium were used as agents of bioaugmentation as well as poultry droppings as agent of biostimulation.

Bioremediation Experimental Design: Twenty (20) grams of un-impacted soil sample having no history of atrazine contamination was dispensed into seven different earthen pots (diameter, $15 \mathrm{~cm}$; depth, $24 \mathrm{~cm}$ ) and labeled A, B, C, D, E, F and G. Isolates of Pseudomonas aeruginosa and Bacillus subtilis were cultured in nutrient broth (NB) liquid while Aspergillus niger was cultured in potato dextrose broth (PDB) liquid medium until they all reached the stationary phase. Cell pellets of the three different isolates were collected and washed twice with sterile phosphate buffered saline (PBS). Thereafter, the cell pellets of Pseudomonas aeruginosa, Bacillus subtilis and Aspergillus niger were suspended in PBS and adjusted to $1.1 \times 10^{6}, 1.3 \times 10^{6}$ and $0.8 \times 10^{6} \mathrm{cfu} \mathrm{g}^{-1}$, respectively. The ratio of Pseudomonas aeruginosa, Bacillus subtilis and Aspergillus niger in the mixture (bacterial-fungal consortium) was 1:1:1 (v:v). Two (2) $\mathrm{ml}$ of de-ionized water was added to each of the pots so as to moisten the soil and then contaminated with $5 \%(\mathrm{w} / \mathrm{w})$ of atrazine herbicide. The contaminated soils in pots B, C and D were correspondingly augmented with Pseudomonas aeruginosa (bioaugmentation), Bacillus subtilis (bioaugmentation) and Aspergillus niger (bioaugmentation); poultry droppings were added to the contaminated soil in pot E (biostimulation); the contaminated soil in pot $\mathrm{F}$ was augmented with mixed bacterial-fungal consortium (consists of Pseudomonas aeruginosa, Bacillus subtilis and Aspergillus niger) (bioaugmentation) and the combined mixture of Pseudomonas aeruginosa, Bacillus subtilis, 
Aspergillus niger and poultry droppings was added to the content in pot $G$ (i.e. combination of bioaugmentation and biostimulation). No microbial isolates and poultry droppings were added to the content in pot $\mathrm{A}$ (natural bioattenuation). The contents in each of the Petri dishes A, B, C, D, E, F, and G were then incubated for 30 days at laboratory ambient temperature. All the experiments were carried out in triplicate. Samples were withdrawn at 5 days interval for residual atrazine determination.

Extraction and Determination of Residual Atrazine Herbicide: Ten (10) millilitre of hexane was added to $1 \mathrm{~g}$ of soil sample and the mixtures were thoroughly shaken for $20 \mathrm{~min}$ in a mechanical shaker to allow for hexane to mix properly and extract all the residual atrazine in the soil sample. The mixtures were left for $48 \mathrm{~h}$ in a separating funnel at the end of which it separated into two layers: the organic upper layer made up of water, hexane and the extracted residual atrazine and the bottom solid layer (residue) made up of soil particles. The upper organic layer was decanted and centrifuged at $4000 \times \mathrm{g}$ for $5 \mathrm{~min}$ after which it was filtered through a clean pad of cotton. The filtrate was evaporated to dryness at $40^{\circ} \mathrm{C}$ in a rotary evaporator to remove the hexane and the residual atrazine was analyzed using gas-liquid chromatography-mass spectrometry. The gas-liquid chromatography conditions were as follows: N2 was used as carrier gas at a flow rate of $3 \mathrm{ml} \mathrm{min}^{-1}$. The capillary column is of $30 \mathrm{~m}$ length $\times 0.32 \mathrm{~mm}$ internal diameter $\times 0.52 \mu \mathrm{m}$ film thickness with 5\% phenyl methyl polysiloxane. The initial temperature of column was set at $180^{\circ} \mathrm{C}$ for $2 \mathrm{~min}$ and then raised at $3{ }^{\circ} \mathrm{C}$ per minute, and finally held at $200{ }^{\circ} \mathrm{C}$ for $15 \mathrm{~min}$. The injector and detector temperatures were set at $230{ }^{\circ} \mathrm{C}$ and $280{ }^{\circ} \mathrm{C}$, respectively.

Kinetics and Estimation of Biodegradation Half-Life: The kinetics of biodegradation is of great significance as it provides at any time the contaminant concentration that will be left or remain and consequently allow for the prediction of the amount likely to be present at some future time (Agarry et al., 2013). The rate of organic compound biodegradation by microbes in soil is often described by a first-order kinetics as given in the Eq. (1) (Agarry et al., 2013):

$$
\ln C_{A}=a+k_{1} t
$$

Where $C_{A}, k_{1}$ and $t$ are the concentration of the contaminant at time $t$, biodegradation rate constant and time, respectively.
Biodegradation half-life $\left(t_{1 / 2}\right)$ is the time taken for half the amount of a substance to be lost or degraded or removed. Biodegradation half-life time can be obtained from the rate constant $k_{1}$ using Eq. (2) (Zahed et al., 2011; Agarry et al., 2013):

$t_{1 / 2}=\frac{\ln 2}{k_{1}}$

Data Analysis: The data were subjected to one-way analysis of variance (ANOVA) at 5\% probability. The data analysis was performed using statistical package for social sciences, version 16.0 (SPSS Inc., Chicago, IL, USA).

\section{RESULTS AND DISCUSSION}

Atrazine Biodegradation: The atrazine biodegradation profile in soil subjected to different bioremediation strategies of natural bioattenuation, bioaugmentation with Pseudomonas aeruginosa, bioaugmentation with Bacillus subtilis, bioaugmentation with Aspergillus niger, biostimulation with poultry droppings, bioaugmentation with bacterial-fungal consortium and combined bioaugmentation and biostimulation is shown in Figure 1. It is observed that the percentage atrazine biodegradation was relatively rapid within the first 15 days of remediation in all the soil subjected to bioaugmentation with Pseudomonas aeruginosa, bioaugmentation with Bacillus subtilis, bioaugmentation with Aspergillus niger, biostimulation with poultry droppings, bioaugmentation with bacterial-fungal consortium and combined bioaugmentation and biostimulation and rapidly continued up to day 30 when compared to that of the soil under natural bioattenuation. At the end of day 30 , the atrazine concentration reduced from $50,000 \mathrm{mg} / \mathrm{kg}$ to $1,451 \pm 240,2,450 \pm 350,8,000 \pm 470$, $480 \pm 40,0$ and $0 \mathrm{mg} / \mathrm{kg}$ corresponding to $97.1 \%$, $95.1 \%, 84 \%, 100 \%, 99 \%$ and $100 \%$ reduction in atrazine contaminated soil subjected to bioaugmentation with Pseudomonas aeruginosa, bioaugmentation with Bacillus subtilis, bioaugmentation with Aspergillus niger, biostimulation with poultry droppings, bioaugmentation with bacterial-fungal consortium, and combined bioaugmentation and biostimulation, respectively.

For the atrazine contaminated soil subjected to natural bioattenuation, the atrazine concentration of 50,000 $\mathrm{mg} / \mathrm{kg}$ reduced to $22,500 \pm 1340 \mathrm{mg} / \mathrm{kg}$ corresponding to $55 \%$ reduction at the end of day 30 . 


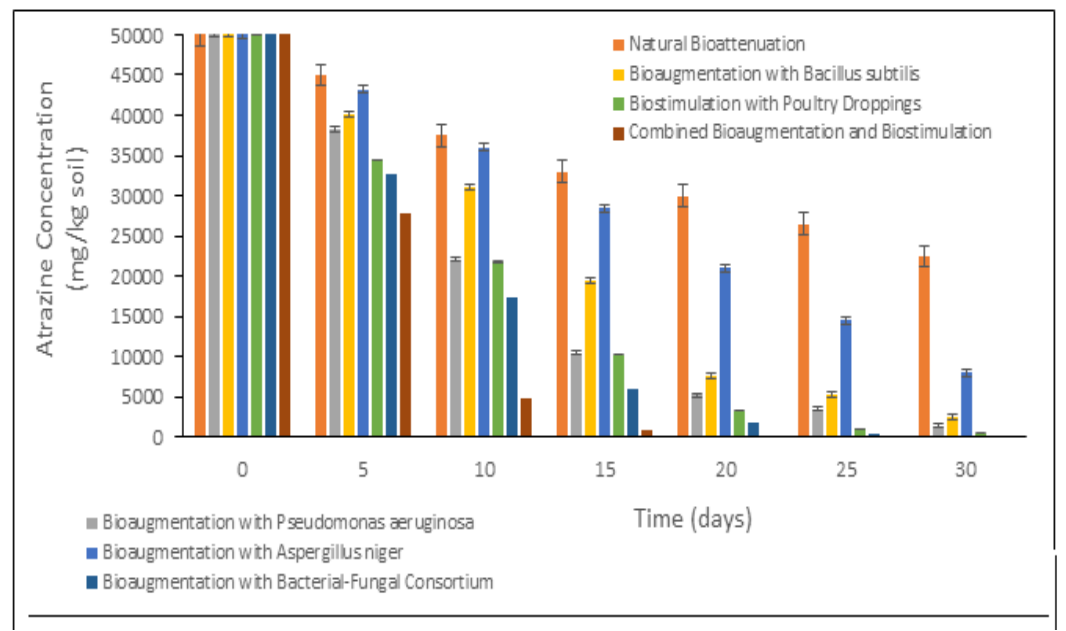

Fig 1.Time course for atrazine biodegradation in soil under natural bioattenuation, bioaugmentation with Pseudomonas aeruginosa, bioaugmentation with Bacillus subtilis, bioaugmentation with Aspergillus niger, biostimulation with poultry droppings, bioaugmentation with bacterial-fungal consortium and combined bioaugmentation and biostimulation. Bars indicate the average of triplicate samples while the error bars show the standard deviation.

This observation showed that during the atrazine biodegradation in soil, bioaugmentation, biostimulation and combination of bioaugmentation and biostimulation individually provided a more effective and enhanced bioremediation response than the natural bioattenuation. The reason(s) for this observation may be due to the fact that biostimulation with poultry droppings provided more nutrients (Table 1) required by the autochthonous microorganisms and more microbial load in the soil (i.e. acting as biostimulation-bioaugmentation agent) (Agarry et al., 2013; Agarry and Jimoda, 2013), while the bioaugmentations with Pseudomonas aeruginosa, Bacillus subtilis and Aspergillus niger either as pure culture or as mixed bacterial-fungal culture increased the level of organic compound degrading microbial species in the soil. Similar observation of enhanced bioremediation or biodegradation of atrazine in soil has been reported for the use of Pseudomonas sp. ADP, mixed bacterial consortium (Pseudomonas sp., Providencia sp., and Bacillus sp.) mixed bacterial consortium (Chenggangzhangella methanolivorans CHL1 and Arthrobacter sp. ATR1) as bioaugmentation agents (i.e. bioaugmentation) (Lima et al., 2009; El-Bestawy et al., 2014; Wang et al., 2018); dairy manure, farmyard manure, citrate and molasses as biostimulation agents (i.e. biostimulation) (Topp et al., 1996; Mukherjee, 2009; Qui et al., 2009; Nousiainen et al., 2015); and mixture of Pseudomonas citronellolis ADP and citrate (i.e. combined bioaugmentation and biostimulation) (Nousiainen et al., 2015). Poultry droppings used as biostimulation agents in this study contained organic nitrogen as part of the nutrients supplied to the soil and consequently played a role in the enhancement of atrazine biodegradation. This is in agreement with the observation of Topp et al. (1996) that used dairy manure as biostimulation agent in the biodegradation of atrazine. However, it is reported that the catabolism of atrazine is repressed in the presence of another nitrogen source and activated when nitrogen is limiting (Dehghani et al., 2013). Thus many investigators have reported the negative effect of nitrogen supplementation on atrazine biodegradation by indigenous microorganisms in soils (Alvey and Crowley, 1995; Abdelhafid et al., 2000; Dehghani et al., 2013). From Figure 1, it is observed that at day 20 and day 30 , complete atrazine biodegradation was attained in contaminated soil subjected to combined bioaugmentation and biostimulation, and bioaugmentation with bacterial-fungal consortium, respectively. This observation indicates that combined bioaugmentation and biostimulation as well as bioaugmentation with bacterial-fungal consortium elicited complete atrazine biodegradation in soil than the individual bioaugmentation with Pseudomonas aeruginosa, bioaugmentation with Bacillus subtilis, bioaugmentation with Aspergillus niger and biostimulation with poultry droppings, respectively. A similar observation has been reported for the use of combined bioaugmentation and biostimulation in eliciting a higher atrazine biodegradation than the use of individual bioaugmentation or biostimulation (Lima et al., 2009; El-Bestawy et al., 2014). 


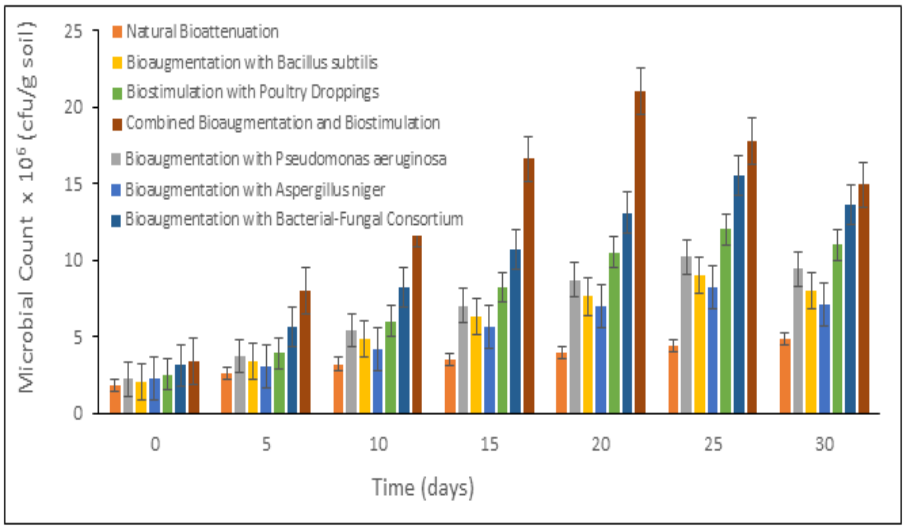

Fig 2 shows the growth profiles of the organic compound degrading organisms in atrazine contaminated soil subjected to different bioremediation strategies of natural bioattenuation, bioaugmentation with Pseudomonas aeruginosa, bioaugmentation with Bacillus subtilis, bioaugmentation with Aspergillus niger, biostimulation with poultry droppings, bioaugmentation with bacterial-fungal consortium and combined bioaugmentation and biostimulation, respectively.

Figure 2. Time course for the growth of organic compound degrading organisms in atrazine contaminated soil under natural bioattenuation, bioaugmentation with Pseudomonas aeruginosa, bioaugmentation with Bacillus subtilis, bioaugmentation with Aspergillus niger, biostimulation with poultry droppings, bioaugmentation with bacterial-fungal consortium and combined bioaugmentation and biostimulation. Bars indicate the average of triplicate samples while the error bars show the standard deviation.

As shown in Figure 2, it is observed that the microbial counts maximally increased from day 0 to day 25 and slightly decreased on day 30 in each of the atrazine contaminated soil subjected to different bioremediation strategies. For the contaminated soil under natural bioattenuation, the microbial count maximally increased from 1.8 to $4.8 \pm 0.4 \times 10^{6} \mathrm{cfu}^{-\mathrm{g}^{-1}}$, while it increased from 2.2 to $10.2 \pm 1.1 \times 10^{6} \mathrm{cfu}^{-\mathrm{g}^{-1}}$, 2.0 to $9.0 \pm 1.2 \times 10^{6} \mathrm{cfu}^{-\mathrm{g}^{-1}}, 2.3$ to $8 \pm 1.4 \times 10^{6} \mathrm{cfu}-\mathrm{g}^{-}$ ${ }^{1}, 2.4$ to $12.0 \pm 1.0 \times 10^{6} \mathrm{cfu}^{-1}, 3.1$ to $15.5 \pm 1.3 \times 10^{6}$ cfu-g $^{-1}$, and 3.4 to $17.8 \pm 1.5 \times 10^{6} \mathrm{cfu}^{-\mathrm{g}^{-1}}$ corresponding to a growth increase of $364 \%, 350 \%, 257 \%, 380 \%$, $400 \%$, and $424 \%$ for atrazine contaminated soil subjected to bioaugmentation with Pseudomonas aeruginosa, bioaugmentation with Bacillus subtilis, bioaugmentation with Aspergillus niger, biostimulation with poultry droppings, bioaugmentation with bacterial-fungal consortium and combined bioaugmentation and biostimulation, respectively. The microbial growth increase in contaminated soil under natural bioattenuation is $167 \%$. These observations revealed that bioaugmentation, biostimulation and the combination of bioaugmentation and biostimulation enhanced the rate of microbial growth which accounted for the higher counts of the microorganisms observed in all the soil subjected to bioaugmentation with Pseudomonas aeruginosa, bioaugmentation with Bacillus subtilis, bioaugmentation with Aspergillus niger, biostimulation with poultry droppings, bioaugmentation with bacterial-fungal consortium and combined bioaugmentation and biostimulation than the microbial counts observed in soil under natural bioattenuation. The higher count in microbial populations observed in atrazine contaminated soil subjected to bioaugmentation, biostimulation and the combination of both may be due to increased level of nutrient which stimulated increase in microbial activities and microbial population as well as increased level of organic compound degrading organisms and activities thus resulted to high carbon demand by the degrading microbes (Agarry et al., 2013).

Evaluation of Atrazine Biodegradation Kinetics and Half-Life: First-order kinetics model equation (Eq. (1)) fitted to the biodegradation data (Figure 1) was used to determine the rate of atrazine biodegradation in the various bioremediation treatments. 


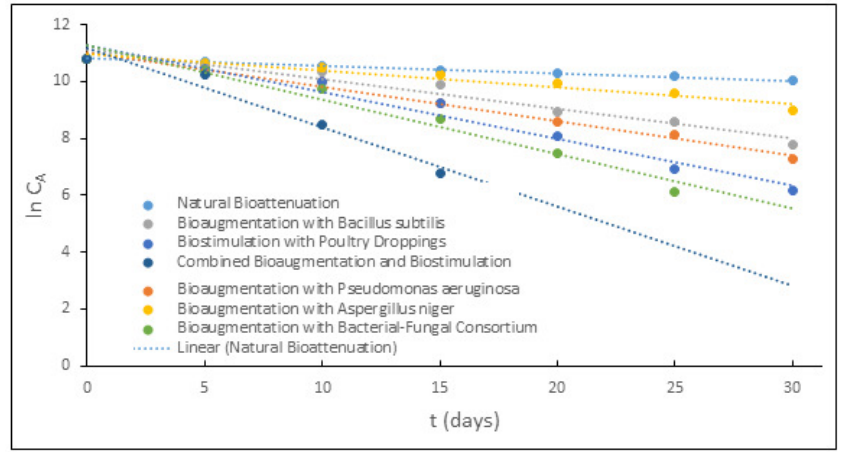

Fig 3. First-order kinetic model fitted to the atrazine biodegradation data under the influence of natural bioattenuation, bioaugmentation with Pseudomonas aeruginosa, bioaugmentation with Bacillus subtilis, bioaugmentation with Aspergillus niger, biostimulation with poultry droppings, bioaugmentation with bacterial-fungal consortium and combined bioaugmentation and biostimulation.

The values of the biodegradation rate constants $\left(k_{1}\right)$ obtained from fitting of the model are presented in Table 2 .

Table 2: First-order kinetic equation with correlation determination $\left(R^{2}\right)$ results of atrazine herbicide biodegradation under the influence of bioaugmentation and biostimulation

\begin{tabular}{lllll}
\hline Bioremediation Strategy & First-Order Kinetic Equation & $k_{1}$ day $^{-1}$ ) & $R^{2}$ & $t_{1 / 2}$ (days) \\
\hline Natural Bioattenuation & $C_{A}=-0.026 t+10.82$ & 0.026 & 0.9948 & 26.7 \\
Bioaugmentation with Pseudomonas aeruginosa & $C_{A}=-0.120 t+11.04$ & 0.120 & 0.9874 & 5.8 \\
Bioaugmentation with Bacillus subtilis & $C_{A}=-0.104 t+11.12$ & 0.104 & 0.9605 & 6.7 \\
Bioaugmentation with Aspergillus niger & $C_{A}=-0.059 t+10.99$ & 0.059 & 0.9457 & 11.7 \\
Bioaugmentation with Bacterial-Fungal Consortium & $C_{A}=-0.191 t+11.26$ & 0.191 & 0.9642 & 3.6 \\
Biostimulation with Poultry Droppings & $C_{A}=-0.164 t+11.27$ & 0.164 & 0.9680 & 4.2 \\
Combined Bioaugmentation and Biostimulation & $C_{A}=-0.279 t+11.17$ & 0.279 & 0.9605 & 2.5 \\
\hline
\end{tabular}

The results in Table 2 as shown by the relatively high coefficient of determination $\left(R^{2}\right)$ values that ranges between 0.94 and 0.99 revealed that atrazine biodegradation adequately fitted well to the first-order kinetic model. The half-life time $\left(t_{1 / 2}\right)$ of atrazine biodegradation was calculated using Eq. (2). The values of $k$ and $t_{1 / 2}$ for the different bioremediation treatments are presented in Table 1. Higher $k$ value indicates higher or faster rate of biodegradation and consequently lower half-life time. It is seen from Table 1 that for soil augmented with the mixture of Pseudomonas aeruginosa, Bacillus subtilis, Aspergillus niger and poultry droppings (i.e. combined bioaugmentation and biostimulation) had a higher $k\left(0.279\right.$ day $\left.^{-1}\right)$ and lower $t_{1 / 2}(2.5$ days $)$ and this is followed by the soil augmented with bacterialfungal consortium which consists of Pseudomonas aeruginosa, Bacillus subtilis and Aspergillus niger ( $k$ $=0.191$ day $^{-1}$ and $t_{1 / 2}=3.6$ days), poultry droppings (i.e. Biostimulation) $\left(k=0.164\right.$ day $^{-1}$ and $t_{1 / 2}=4.2$ days), Pseudomonas aeruginosa $\left(k=0.120\right.$ day $^{-1}$ and $t_{1 / 2}=5.8$ days), Bacillus subtilis $\left(k=0.104\right.$ day $^{-1}$ and $t_{1 / 2}=6.7$ days $)$, and Aspergillus niger $\left(k=0.059\right.$ day $^{-}$ ${ }^{1}$ and $t_{1 / 2}=11.7$ days), respectively. A $k$ value of 0.026 day $^{-1}$ and $t_{1 / 2}$ of 26.7 days was obtained for atrazine biodegradation in the non-augmented soil (natural bioattenuation). The $k$ value is lower and the $t_{1 / 2}$ value is higher than the values obtained for the atrazine contaminated soil subjected to either bioaugmentation, biostimulation or both. This observation indicates that atrazine biodegradation in soil undergoing natural bioattenuation (bioremediation) is slower and with a higher biodegradation half-life time.

Effectiveness of the Different Bioremediation Strategies: A one-way Analysis of Variance (ANOVA) was carried out to compare the atrazine biodegradation efficiency of the different bioremediation strategies adopted in this study and the result is presented in Table 3 . 


\begin{tabular}{clllll} 
Table 3: Analysis of variance (ANOVA) & for the different bioremediation strategies \\
\hline Source & $\begin{array}{l}\text { Sum of } \\
\text { squares }\end{array}$ & $\begin{array}{l}\text { Degree of } \\
\text { freedom }\end{array}$ & $\begin{array}{l}\text { Mean of } \\
\text { squares }\end{array}$ & $F$-value & $P$-value \\
\hline Treatment & 0.1307 & 6 & 0.0218 & 6929.27 & $1.11 \mathrm{E}-16$ \\
Error & 0.000 & 14 & 0.000 & & \\
Total & 0.1307 & 20 & & & \\
\hline
\end{tabular}

The result suggests that all the bioremediation strategies (natural bioatenuation, bioaugmentation, biostimulation, and combined bioaugmentation and biostimulation) had a statistically significant influence on the atrazine biodegradation in soil at the $5 \%$ probability level $(\mathrm{p}=0.05)$. Therefore, the effectiveness of each strategies was tested. Through evaluation of the rate constant of atrazine biodegradation in non-augmented soil (natural bioattenuation) and augmented soil (bioaugmentation and/or biostimulation), the bioremediation efficiency
(E (\%)) was calculated at the end of 30-day bioremediation period using Eq. (3):

$\mathrm{E}(\%)=\frac{k_{(\text {Aug })}-k_{(\mathrm{Non}-A)}}{k_{(\text {Aug })}} \times 100$

Where, $k_{(A u g)}$ is the rate constant of atrazine biodegradation in the augmented soil, and $k_{(N o n-A)}$, the rate constant of atrazine biodegradation in the nonaugmented soil. The E (\%) results are shown in Table 4.

Table 4: Percentage biodegradation of atrazine and bioremediation efficiency of the different bioremediation strategies at the end of 30

\begin{tabular}{lll}
\multicolumn{3}{c}{ days } \\
\multicolumn{1}{c}{$k$ Bioremediation Strategy } & E (\%) \\
& 1 ) & \\
\hline Natural Bioattenuation & 0.026 & - \\
Bioaugmentation with Pseudomonas aeruginosa & 0.120 & 78.3 \\
Bioaugmentation with Bacillus subtilis & 0.104 & 75 \\
Bioaugmentation with Aspergillus niger & 0.059 & 56 \\
Biostimulation with Poultry Droppings & 0.164 & 84.1 \\
Bioaugmentation with Bacterial-Fungal Consortium & 0.191 & 86.4 \\
Combined Bioaugmentation and Biostimulation & 0.279 & 90.7 \\
\hline
\end{tabular}

The results in Table 4 generally revealed that there are relative differences in the bioremediation efficiencies $(\mathrm{E}(\%))$ of the different strategies (bioaugmentation with Pseudomonas aeruginosa, bioaugmentation with Bacillus subtilis, biostimulation with poultry droppings, bioaugmentation with bacterial-fungal consortium and combined bioaugmentation and biostimulation) utilized in the soil bioremediation of atrazine.

Nevertheless, to actually determine the significant difference in the bioremediation efficiencies, post hoc comparisons using Tukey's (HSD) test at 5\% probability level were out between the different strategies.

The difference in mean $\mathrm{k}$ (rate constant) between pairs of strategies was greater than the HSD value, hence, the grouping of mean k using the Tukey's test for the different bioremediation strategies as presented in Table 5 reveals that there are significant differences in the biodegradation rate and thus in the bioremediation efficiencies of natural bioattenuation, bioaugmentation with Pseudomonas aeruginosa, bioaugmentation with Bacillus subtilis, bioaugmentation with Aspergillus niger, biostimulation with poultry droppings, bioaugmentation with bacterial-fungal consortium and combined bioaugmentation and biostimulation.

The Tukey's test showed that there are significant differences in the bioremediation efficiencies between each of the different bioremediation strategies (natural bioattenuation, bioaugmentation with Pseudomonas aeruginosa, bioaugmentation with Bacillus subtilis, bioaugmentation with Aspergillus niger, biostimulation with poultry droppings, bioaugmentation with bacterial-fungal consortium and combined bioaugmentation and biostimulation).

Therefore, in comparison between the different bioremediation strategies, combined bioaugmentation and biostimulation suggests to be relatively more effective with higher E (\%) (90.7\%).

This is followed by bioaugmentation with bacterialfungal consortium $(86.4 \%)$, biostimulation with poultry droppings $(84.1 \%)$, bioaugmentation with Pseudomonas aeruginosa (78.3\%), bioaugmentation with Bacillus subtilis (75\%) and bioaugmentation with Aspergillus niger (56\%), respectively. 


\begin{tabular}{llll} 
Table 5: Grouping of k mean for the different bioremediation strategies computed by Tukey's method \\
\hline Bioremediation Strategy & $k_{1}$ Mean $^{*}$ & $\begin{array}{l}\text { Standard } \\
\text { Deviation }\end{array}$ & P-Value \\
\hline Natural Bioattenuation & $0.026^{\mathrm{A}}$ & 0.0006 & $p<0.01$ \\
Bioaugmentation with Pseudomonas aeruginosa & $0.120^{\mathrm{B}}$ & 0.0012 & $p<0.01$ \\
Bioaugmentation with Bacillus subtilis & $0.104^{\mathrm{C}}$ & 0.0006 & $p<0.01$ \\
Bioaugmentation with Aspergillus niger & $0.059^{\mathrm{D}}$ & 0.0012 & $p<0.01$ \\
Bioaugmentation with Bacterial-Fungal Consortium & $0.191^{\mathrm{E}}$ & 0.0012 & $p<0.01$ \\
Biostimulation with Poultry Droppings & $0.164^{\mathrm{F}}$ & 0.0012 & $p<0.01$ \\
Combined Bioaugmentation and Biostimulation & $0.279^{\mathrm{G}}$ & 0.0012 & $p<0.01$ \\
\hline \multicolumn{4}{r}{ "Means that do not share the same letter are significantly different }
\end{tabular}

Conclusions: From this study, it can be concluded that the use of Pseudomonas aeruginosa, Bacillus subtilis, Aspergillus niger and poultry droppings as bioaugmentation and biostimulation agents accelerates or enhances the rate of atrazine biodegradation in soil and thus its removal from contaminated soil. Complete atrazine biodegradation or removal with higher biodegradation rate and lower biodegradation half-life can be attained at reduced remediation time using combined bioaugmentation and biostimulation strategy as compared to bioaugmentation or biostimulation alone.

\section{REFERENCE}

Abdelhafid, R; Houot, S; Barriuso, E (2000). Dependence of atrazine degradation on $\mathrm{C}$ and $\mathrm{N}$ availability in adapted and non-adapted soils. Soil Biology and Biochemistry, 32 (3): 389-401.

Ackerman, F (2007). The economics of atrazine. Int. J. Occup. Environ. Health 13: 437-445.

Agarry, SE (2018). Evaluation of the effects of inorganic and organic fertilizers and activated carbon on bioremediation of soil contaminated with weathered crude oil. J. Appl. Sci. Environ. Manage. 22 (4): 587 - 595.

Agarry, SE; Aremu, MO; Aworanti, OA (2013). Kinetic modelling and half-life study on enhanced soil bioremediation of bonny light crude oil amended with crop and animal-derived organic wastes. J. Pet Environ. Biotechnol. 4: 137.

Agarry, SE; Jimoda, LA (2013). Application of carbon-nitrogen supplementation from plant and animal sources in in-situ soil bioremediation of diesel oil: experimental analysis and kinetic modelling. J. Environ. Earth Sci. 3 (7): 51-63.

Agnello, AC; Bagard, M; van Hullebusch, ED; Esposito, G; Huguenot, D (2016). Comparative bioremediation of heavy metals and petroleum hydrocarbons co-contaminated soil by natural attenuation, phytoremediation, bioaugmentation and bioaugmentation-assisted phytoremediation. Sci. Total Environ. 563: 693-703.

Alvey, S; Crowley, DE (1995). Influence of organic amendments on biodegradation of atrazine as a nitrogen source. J. Environ. Quality 24 (6): 11561162.

APHA (2005). Standard Methods for Examination of water and wastewater. American Public Health Association, Washington D.C.

Cao, B; Zhang, Y; Wang, Z; Li, M; Yang, F; Jiang, D; Jiang, $Z$ (2018). Insight into the variation of bacterial structure in atrazine-contaminated soil regulating by potential phytoremediator: Pennisetum americanum (L.) K. Schum. Front. Microbiol. 9: 864-874.

Correia, FV; Macrae, A; Guilherme, LR; Langenbach, $\mathrm{T}$ (2007). Atrazine sorption and fate in a Ultisol from humid tropical Brazil. Chemosphere 67: 847-854.

Danrong, Z; Haixia, D; Yiqing, G; Yanan, T (2009). Comparison of atrazine sorption and degradation properties in packed and intact soil columns: Proceedings of 3rd International Conference on Bioinformatics and Biomedical Engineering, Beijing, Pg. 1-3.

Dehghani, M; Nasseri, IS; Hashemi, H (2013). Study of the bioremediation of atrazine under variable carbon and nitrogen sources by mixed bacterial consortium isolated from corn field soil in Fars province of Iran. J. Environ. Public Health 2013, Article ID 973165, 7 pages http://dx.doi.org/10.1155/2013/973165

Dehghani, M; Nasseri, S; Amin, S; Naddafi, K; Yunesian, M et al. (2005). Atrazine adsorption desorption behaviour in Darehasaluie Kavar corn field soil in Fars province of Iran. Iran J. Environ. Health Sci. Eng. 2: 221-228. 
Dehghani, M; Nasseri, S; Amin, SA; Zamanian, Z (2010). Assessment of atrazine distribution in Shiraz soils, south of Iran. Pak. J. Biol. Sci. 13 (2): 66-72.

El-Bestawy E; Sabir, J; Mansy, AH; Zabermawi, N (2014). Comparison among the efficiency of different bioremediation technologies of atrazinecontaminated soils. J. Bioremed. Biodeg. 5 (5): 1000237.

Extension Toxicology Network (1996) Pesticide Information Profile: Atrazine (Cooperative Extension Offices of Cornell University, Oregon State University, the University of Idaho, and the University of California at Davis and the Institute for Environmental Toxicology, Michigan State University.

Ghosh, PK; Philip, LIGY (2006). Environmental significance of atrazine in aqueous systems and its removal by biological processes: an overview. Global NEST J. 8(2):159-178

Granados, PR; Villaverde, PC (1996). Microbiología. Bacteriología: características y clasifcación bacteriana. Paraninfo, Barcelona. España. 298 pp

Gregoire, C; Elsaesser, D; Huguenot, D; Lange, J; Lebeau T et al. (2008). Mitigation of agricultural nonpoint-source pesticide pollution in artificial wetland ecosystems: A Review. Environ. Chem. Lett. 2: 293-338.

Imfeld, G; Vuilleumier, S (2012). Measuring the effects of pesticides on bacterial communities in soil: a critical review. Eur. J. Soil Biol. 49: 22-30.

Krieg, NR; Holt, JG; Sneath, PHA; Stanley, JT; William, ST (1994). 'Bergey's Manual of Determinative Bacteriology'. Baltimore, USA, William and Wilkins.

Lasserre, JP; Fack, F; Revets, D; Planchon, S; Renaut, J; Hoffmann, L., et al. (2009). Effects of the endocrine disruptors atrazine and PCB 153 on the protein expression of MCF-7 human cells. $J$. Proteome Res. 8: 5485-5496.

Lima, D; Viana, P; André, S; Chelinho, S; Costa, C; Ribeiro, R; Sousa, JP; Fialho, AM; Viegas, CA (2009). Evaluating a bioremediation tool for atrazine contaminated soils in open soil microcosms: the effectiveness of bioaugmentation and biostimulation approaches. Chemosphere 74:187-192.
Marecik, R; KrÃliczak, P; Czaczyk, K; BiaÅ,as, W; Olejnik, A et al. (2008). Atrazine degradation by aerobic microorganisms isolated from the rhizosphere of sweet flag (Acorus calamus L.). Biodegradation 19: 293-301.

Mukherjee, I (2009). Effect of organic amendments on degradation of atrazine. Bull. Environ. Contam. Toxicol. 83 (6): 832-835.

Muñoz-Leoz, B; Ruiz-Romera, E; Antigüedad, I; Garbisu, C (2011). Tebuconazole application decreases soil microbial biomass and activity. Soil Biol. Biochem. 43: 2176-2183.

Nasseri, S; Dehghani, M; Amin, S; Naddafi, K; Zamanian, Z (2009). Fate of atrazine in the agricultural soil of corn fields in fars province of Iran. Iranian J. Environ. Health Sci. Eng. 6 (4): 223-232.

Nousiainen, AO; Björklöf, K; Sagarkar, S; Nielsen, JL; Kapley, A; Jørgensen, KS (2015). Bioremediation strategies for removal of residual atrazine in the boreal groundwater zone. Appl. Microbiol. Biotechnol. DOI 10.1007/s00253-0156828-2

Pandey, J; Chauhan, A; Jain, R K (2009). Integrative approaches for assessing the ecological sustainability of in situ bioremediation. FEMS Microbiol. Rev. 33: 324-375.

Qiu, Y; Pang, H; Zhou, Z; Zhang, P; Feng, Y; Sheng, GD (2009). Competitive biodegradation of dichlobenil and atrazine coexisting in soil amended with a char and citrate. Environ. Poll. 157 (11): 2964-2969.

Rousseaux, S; Hartmann, A; Soulas, G (2001). Isolation and characterisation of new Gramnegative and Gram-positive atrazine degrading bacteria from different French soils. FEMS Microbiol. Ecol. 36(2-3): 211-222.

Solomon, RD; Kumar, A; Satheeja Santhi, V (2013). Atrazine biodegradation efficiency, metabolite detection, and trzD gene expression by enrichment bacterial cultures from agricultural soilAtrazine biodegradation efficiency, metabolite detection, and $t r z D$ gene expression by enrichment bacterial cultures from agricultural soil. J. Zhejiang Univ. Sci. B14 (12): 1162-1172.

Sopid, S (2016). Isolation and characterization of atrazine-degrading xanthomonas sp. ARB2 and 
its use in bioremediation of contaminated soils. Int. J. Environ. Sci. Dev. 7 (5): 351-354.

Topp, E; Tessier, L; Gregorich, EG (1996). Dairy manure incorporation stimulates rapid atrazine mineralization in an agricultural soil. Can. J. Soil Sci. 76 (3): 403-409.

VanLeeuwen, JA; Waltner-Toews, D; Abernathy, T; Smit, B; Shoukri, M (1999). Associations between stomach cancer incidence and drinking water contamination with atrazine and nitrate in Ontario (Canada) agroecosystems, 1987-1991. Int. J. Epidemiol. 28 (5): 836-840.

Wang, J; Li, X; Li, X; Wang, H; Su, Z; Wang, X; Zhang, H (2018). Dynamic changes in microbial communities during the bioremediation of herbicide (chlorimuron-ethyl and atrazine) contaminated soils by combined degrading bacteria. PLoS ONE 13(4): e0194753. https://doi.org/10.1371/journal.pone.0194753

Wang, J; Zhu, L; Wang, Q; Wang, J; Xie, H (2014). Isolation and characterization of atrazine mineralizing Bacillus subtilis strain HB-6. PLoS ONE ;9:e107270
Wang, Q; Xie, S (2012). Isolation and characterization of a high-efficiency soil atrazine-degrading Arthrobactersp. Strain. Int. Biodeter. Biodegr. 71: 61-66.

Zahed, MA; Abdul Aziz, H; Isa, MH; Mohajeri, L; Mohajeri, S; Kutty, SRM (2011). Kinetic modeling and half- life study on bioremediation of crude oil dispersed by Corexit 9500. J. Hazard Mater. 185: 1027 - 1031.

Zhao, X; Wang, L; Ma, F; Bai, S; Yang, J; Qi, S (2017). Pseudomonas sp. ZXY-1, a newly isolated and highly efficient atrazine-degrading bacterium, and optimization of biodegradation using response surface methodology. J. Environ. Sci. 54: 152-159.

Zhao, X; Wang, L; Ma, F; Yang, J (2018). Characterization of an efficient atrazine-degrading bacterium, Arthrobacter sp. ZXY-2: an attempt to lay the foundation for potential bioaugmentation applications. Biotechnol Biofuels 11:113. 